included Dr Richard Simpson, Miss Dorothy Broadman, Senior Social Work Adviser, Mr J. C. Anderson, Deputy Unit Leader, Scottish Special Housing and Dr I. E. Thomson of the Department of Medical Ethics and Education of the University of Edinburgh.

On 2 December 1977 the Division will meet in Glasgow to hear reports of research work in the Department of Psychological Medicine in the University of Glasgow and from the Department of Pharmaceutical Technology in the University of Strathclyde, the MRC Virology Unit and the MRC Blood Pressure Unit. The Second Annual Dinner will be held in the Royal College of Physicians and Surgeons of Glasgow when it is again intended that newly admitted members of the Division will be received as guests and welcomed by the President.

Programmes of meetings for 1978 are in preparation. We meet at Gogarburn Hospital, Edinburgh, on Io March; the Summer meeting and AGM will be held on 16 June, the place yet to be decided. Further meetings will be held on 22 September and I December 1978 .

In addition to all these activities the Specialist Sections of the Division have continued to have a very active programme of meetings and weekend conferences. The Executive Committee has met six times each year and has dealt with a considerable volume of important business. Amongst the items of particular significance have been the production of a report of a working party chaired by $\mathrm{Dr} J$. W. Affleck on 'The Psychiatrist's Contribution to the Care of the Elderly'. This report has been circulated to Health Boards, Local Health Councils, Directors of Social Work and a number of other interested

\section{TO OVERSEAS MEMBERS}

It is possible for issues of the British Fournal of Psychiatry and College papers to be sent to Fellows, Members and Affiliates overseas by Air Mail on payment of an additional annual charge, as indicated below.

$\begin{array}{lccc}\text { Bulletin } & \begin{array}{c}\text { Journal and } \\ \text { only }\end{array} & \begin{array}{c}\text { Meetings } \\ \text { only }\end{array} \\ \text { Europe } & £ 1.26 & £ 4.20 & 66 \mathrm{p} \\ \text { Zone A } & £ 1.20 & £ 6.24 & 54 \mathrm{p} \\ \text { Zone B } & £ 1.26 & £ 7.44 & 64 \mathrm{p} \\ \text { Zone C } & £ 1.50 & £ 9.96 & 88 \mathrm{p}\end{array}$

Those wishing to take advantage of this service should notify the Finance Officer of the College, who will let them know the appropriate rate, which varies from country to country. parties, and there is encouraging evidence that the Scottish Home and Health Department plan to accord higher priority to this aspect of the mental health service. There have also been a number of meetings with representatives of the Scottish Universities and with the Scottish Home and Health Department regarding staffing and training in psychotherapy, and the SHHD are now actively studying the implications of the separate designation of consultants and senior registrars in psychotherapy in Scotland. Members of the Executive Committee have had joint meetings with the Scottish Branch of the Institute of Health Service Administrators to discuss mutual problems in the administration of the Mental Health Services, and we have also had joint discussions with the Scottish Branch of the Royal College of Nursing and with the Association of Psychiatric Nurse Tutors in Scotland. Representatives of the Division have continued to play an active part in the College approval exercise. Dr J. K. Binns has now stepped down as Chairman of the Approval Panel and has been succeeded by $\mathrm{Dr}$ W. E. S. Kiernan of Glasgow who has recently returned from spending a year as a WHO adviser in India.

Currently under discussion is a proposal to meet Scottish Members of Parliament who have expressed an interest in mental health matter 3 in order to discuss further ways in which the Scottish Mental Health Service can be improved.

I hope that any member of the College travelling in Scotland on holiday or on business will try to attend one of our meetings, where a warm welcome is assured.

\section{G. C. Tmmury, Divisional Secretary}

\section{PAPERS FOR THE ANNUAL MEETING, 1978}

The Programmes and Meetings Committee invites members of the College to submit papers on miscellaneous topics for presentation at the Annual Meeting, which is to be held on 4, 5 and 6 July 1978 . Depending on the number offered, the Committee is prepared to make arrangements for parallel sessions to enable as many papers as possible to be read. I would be grateful to hear from members who have papers which they would like to present. The closing date for the receipt of summaries is 28 February 1978.

C. M. B. PARE Honorary Secretary, Programmes and Meetings Committee 